\title{
Cuidados paliativos de enfermagem a pacientes com feridas neoplásicas
}

\author{
Palliative nursing care for patients with neoplastic wounds \\ Cuidados de enfermería paliativos para pacientes con heridas neoplásicas
}

Elisá Victória Silva e Silva ${ }^{1}$, Hayla Nunes da Conceição

\begin{abstract}
${ }^{1}$ Graduanda em Enfermagem pela Universidade Estadual do Maranhão. São Luís - Maranhão.
${ }^{2}$ Enfermeira. Especialista em Saúde Pública e Docência no Ensino Superior pela Faculdade

Evangélica do Meio Norte. Aluna do Programa de Pós-Graduação em Saúde e Comunidade na Universidade Federal do Piauí. Teresina - Piauí.
\end{abstract}

\section{RESUMO}

Objetivo: Descrever as evidências científicas disponíveis na literatura sobre os cuidados paliativos de enfermagem a pacientes com feridas neoplásicas. Métodos: Trata-se de uma revisão integrativa, realizada no LILACS, MEDLINE e BDENF, a partir dos descritores: Oncologia, Cuidados Paliativos, Neoplasias Cutâneas. Resultados: Analisaram-se 8 artigos, organizados nas seguintes categorias: 1) Assistência de enfermagem no controle do odor e exsudato em feridas neoplásicas; 2) Cuidados paliativos de enfermagem no controle da dor e hemorragias em feridas neoplásicas; 3) Atuação assistencial de enfermagem aos impactos psicossociais em pacientes com feridas neoplásicas em tratamento paliativo; 4) A importância da educação permanente dos profissionais de enfermagem que atuam no cuidado paliativo de feridas neoplásicas. Conclusões: A enfermagem atua proporcionando assistência humanizada aos pacientes em cuidados paliativos, a fim de minimizar o desconforto das feridas neoplásicas.

Autor de Correspondência:

*Hayla Nunes da Conceição. E-mail: haylanunes_cx@hotmail.com 
Palavras-chaves: Oncologia. Cuidados Paliativos. Neoplasias Cutâneas. Humanização da Assistência.

\begin{abstract}
Objective: To describe the scientific evidence available in the literature about palliative nursing care for patients with neoplastic wounds. Methods: This is an integrative review, carried out at LILACS, MEDLINE and BDENF, based on the descriptors: Oncology, Palliative Care, Skin Neoplasms. Results: Eight articles were analyzed, organized into the following categories: 1) Nursing assistance in the control of odor and exudate in neoplastic wounds; 2) Palliative nursing care to control pain and hemorrhage in neoplastic wounds; 3) Nursing care performance to psychosocial impacts in patients with neoplastic wounds undergoing palliative treatment; 4) The importance of continuing education for nursing professionals who work in palliative care for neoplastic wounds. Conclusions: Nurses work providing humanized assistance to patients in palliative care, in order to minimize discomfort from neoplastic wounds.
\end{abstract}

Keywords: Medical Oncology. Palliative Care. Skin Neoplasms. Humanization of Assistance.

\title{
RESUMEN
}

Objetivo: Describir la evidencia científica disponible en la literatura sobre cuidados paliativos de enfermería para pacientes con heridas neoplásicas. Métodos: Esta es una revisión integradora, realizada en LILACS, MEDLINE y BDENF, basada en los descriptores: Oncología, Cuidados Paliativos, Neoplasias de la Piel. Resultados: se analizaron 8 artículos, organizados en las siguientes categorías: 1) Asistencia de enfermería en el control del olor y exudado en heridas neoplásicas; 2) Cuidados de enfermería paliativos para controlar el dolor y la hemorragia en heridas neoplásicas; 3) Desempeño de la atención de enfermería ante los impactos psicosociales en pacientes con heridas neoplásicas sometidas a tratamiento paliativo; 4) La importancia de la educación continua para los profesionales de enfermería que trabajan en cuidados paliativos para heridas neoplásicas. Conclusiones: la enfermería funciona brindando asistencia humanizada a los pacientes en cuidados paliativos para minimizar la incomodidad de las heridas neoplásicas.

Palabras clave: Oncología Médica Cuidados Paliativos. Neoplasias Cutáneas. Humanización de la Atención 


\section{INTRODUÇÃO}

O câncer é uma das doenças mais temidas no mundo inteiro. Grande parte desse medo é causado pela ausência de tratamento efetivo para a maioria dos tumores, em decorrência da elevada taxa de diagnósticos tardios, que interfere diretamente na realização de tratamento precoce e até na possibilidade de cura, quando a neoplasia se encontra em estágio avançado ${ }^{1}$. As neoplasias representam um desafio para a saúde pública devido a elevadas taxas de morbimortalidade e por serem amplamente disseminadas em todos os países. A Organização Mundial da Saúde pressupõe que em 2025 ocorrerão mais de 20 milhões de novos casos no mundo 2 .

Estima-se que entre os pacientes portadores de neoplasias, cerca de 5 a 10\% desenvolverão feridas neoplásicas em decorrência das doenças, as quais são comumente originadas por neoplasias cutâneas primárias ou metástases, apresentando maior predominância em pacientes de faixa etária entre 60 a 70 anos de idade. As úlceras neoplásicas estão associadas à imprudência do paciente e sua demora para procurar um auxílio médico, dificuldade de acesso aos serviços de saúde e/ou o diagnóstico tardio do profissional para dar início ao tratamento da doença ${ }^{3}$.

O diagnóstico precoce e o estadiamento correto são os pilares para subsidiar a tomada de decisão terapêutica para cada caso. A biologia do câncer, portanto, deve ser bem compreendida pelos profissionais da saúde, uma vez que é fundamental para realizar a detecção e tratamento adequado e em tempo oportuno, garantindo assim uma melhor qualidade de vida e/ou sobrevida ao doente ${ }^{4}$.

O tratamento das feridas neoplásicas ocorre, na maior parte dos casos, de forma paliativa. Ou seja, a intenção é minimizar sinais e sintomas quando a evolução da doença não permite a possibilidade de cura ou controle, proporcionando a melhora na qualidade de vida aos pacientes ${ }^{5}$.
O enfermeiro é o profissional que habitualmente é responsável pela realização do tratamento de feridas. Dessa maneira, é necessário que o profissional tenha competência para identificar, avaliar e tratar as feridas neoplásicas, proporcionando uma assistência integral ao paciente e à sua família ${ }^{6}$. Além disso, cabe ao enfermeiro, como membro da equipe multiprofissional, prestar assistência pautada nas múltiplas dimensões do indivíduo - dimensões física, psíquica, social, espiritual e familiar do paciente -, a fim de melhorar sua qualidade de vida durante seus últimos dias, uma vez que o paciente que vive com doença oncológica avançada e apresenta ferida neoplásica possui um alto grau de vulnerabilidade nas dimensões que o integram como ser humano ${ }^{7}$.

Em pacientes com ferida neoplásica, o enfermeiro deve considerar durante a avaliação da lesão os seguintes aspectos: tamanho, profundidade, área de envolvimento, coloração, extensão, odor, exsudato, sangramento, dor, prurido, descamação, fístulas, abscessos, limitação física, metástases, adequação de roupas e curativos para o paciente ${ }^{8}$. Dessa forma, o Instituto Nacional do Câncer (INCA) ${ }^{8}$ divulgou um manual de ações de enfermagem para pacientes com doença oncológica avançada que apresentam feridas neoplásicas, com o objetivo de uniformizar as intervenções avaliativas e terapêuticas para melhor cuidar destes pacientes.

Assim, o cuidado humanizado de enfermagem é necessário para uma assistência paliativa de qualidade, que minimize o desconforto, a dor e os transtornos psicossociais que podem ser gerados pelas feridas oncológicas ${ }^{7,8}$. Dessa forma, o presente trabalho tem como objetivo descrever as evidências científicas disponíveis na literatura acerca dos cuidados paliativos de enfermagem a pacientes com feridas neoplásicas. 


\section{MÉTODO}

Trata-se de uma revisão integrativa, que consiste em uma metodologia que proporciona a síntese do conhecimento e incorporação da aplicabilidade de resultados de estudos significativos na prática, ou seja, os seus resultados permitem a execução da pratica baseada em evidências 9 . Nessa perspectiva, este estudo de revisão integrativa da literatura se baseou na seguinte questão norteadora: quais os cuidados paliativos de enfermagem a pacientes com feridas neoplásicas?

Para a investigação, realizou-se um levantamento da produção científica relacionada a feridas neoplásicas. A busca das informações foi realizada em fontes de dados virtuais: Literatura Latino Americana e do Caribe em Ciências da Saúde (LILACS), Medical Literature Analysis and Retrieval System Online (MEDLINE) e Base de Dados de Enfermagem (BDENF), a partir dos descritores: Oncologia, Cuidados Paliativos e Neoplasias Cutâneas. Consultou-se as bases de dados no período de março a abril de 2020. É importante frisar que a busca nessas bases de dados (MEDLINE, LILACS e BDENF) foi realizada através do portal da Biblioteca Virtual em Saúde (BVS).

A seleção dos estudos a serem analisados foi realizada com base nos seguintes critérios de inclusão: 1) Texto na íntegra; 2) Constar na base de dados MEDLINE, LILACS, BDENF; 3) Artigos na língua portuguesa; 4) Serem pesquisas publicadas no período de 2016 a 2019. Os critérios de exclusão foram: 1) Repetição de um mesmo artigo encontrado em mais de um banco de dados; 2) Falta de associação com o tema da pesquisa; 3) Não constar de texto completo apresentando-se sob a forma de resumo. Após a aplicação dos critérios de inclusão, 17 artigos foram selecionados para a análise. Depois de uma análise sistemática, identificaram-se 8 trabalhos que preenchiam os critérios de inclusão. Por fim, foram feitas leituras criteriosas para a avaliação dos artigos selecionados que compõem o presente estudo (Fluxograma 1).
Fluxograma 1 - Disposição sistemática dos trabalhos encontrados

BIBLIOTECA VIRTUAL DE SAÚDE

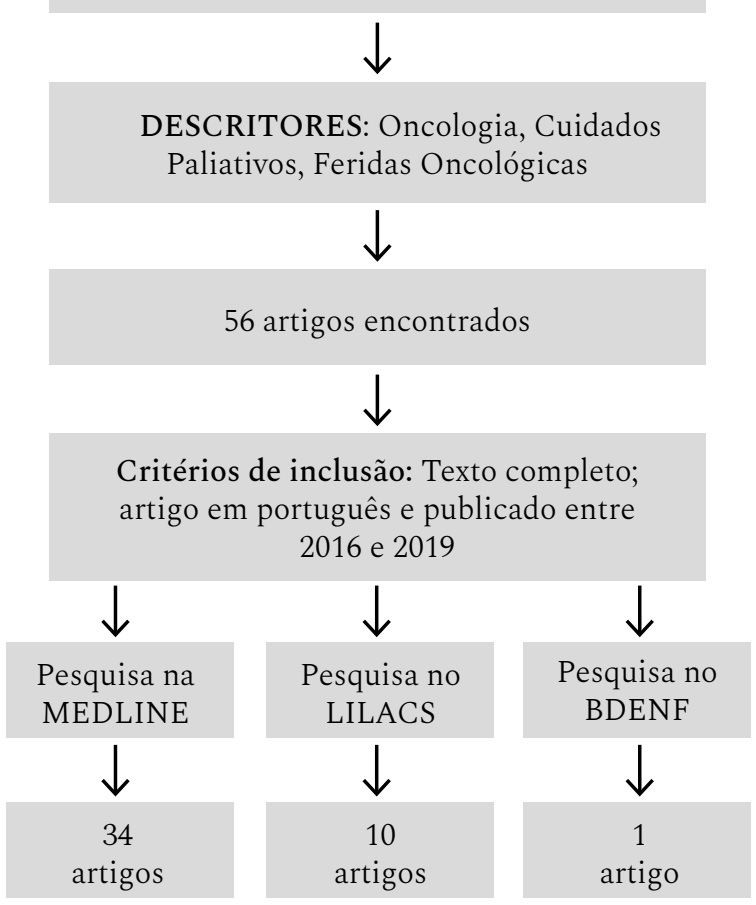

Critérios de exclusão: Texto incompleto; artigos que não se enquadravam na temática e artigos repetidos

Foram selecionados 08 artigos para leitura e análise que se enquadravam no objetivo do estudo

\section{RESULTADOS}

Selecionaram-se, neste estudo, oito artigos que atenderam à questão norteadora da pesquisa. Extraíram-se dos artigos, desse modo, dados quanto ao periódico da publicação, ao tipo de estudo, ao autor principal, ao período de publicação e ao objetivo. Obteve-se, como resultados, o total de 5 (62,5\%) tipos 
de estudo de revisão integrativa da literatura, $2(25 \%)$ de transversal e $12,5 \%$ de descritivo. A maior parte dos artigos foram publicados em 2019 ( $\mathrm{n}=4 ; 50 \%)$ e $2(25 \%)$ na Revista Brasileira de Enfermagem (Quadro 1).

Quadro 1 - Distribuição dos artigos segundo o periódico, o tipo de estudo, o autor, o ano e os objetivos.

\begin{tabular}{|c|c|c|c|c|}
\hline ARTIGOS & AUTORES, ANO & PERIÓDICO & OBJETIVO & $\begin{array}{l}\text { TIPO DE } \\
\text { ESTUDO }\end{array}$ \\
\hline $\mathrm{A} 1^{10}$ & $\begin{array}{l}\text { Freitas MSHS, } \\
\text { Pacheco PQC; } \\
\text { Souza SR, } 2016 .\end{array}$ & $\begin{array}{l}\text { Revista de } \\
\text { Enfermagem } \\
\text { Atual In Derme }\end{array}$ & $\begin{array}{l}\text { Descrever e analisar as evidências } \\
\text { científicas encontradas na literatura } \\
\text { sobre a qualidade de vida do paciente } \\
\text { portador de feridas neoplásicas. }\end{array}$ & $\begin{array}{c}\text { Revisão integrativa } \\
\text { da literatura }\end{array}$ \\
\hline $\mathrm{A} 2^{3}$ & $\begin{array}{l}\text { Santos WA, Fuly } \\
\text { PSC, Santos } \\
\text { MLSC, Souto MD, } \\
\text { Reis CM, Castro } \\
\text { MCF, } 2017 .\end{array}$ & $\begin{array}{l}\text { Revista } \\
\text { Enfermagem } \\
\text { UFPE on-line }\end{array}$ & $\begin{array}{l}\text { Identificar as evidências científicas } \\
\text { sobre o isolamento social em pacientes } \\
\text { com odor fétido em feridas neoplásicas. }\end{array}$ & $\begin{array}{c}\text { Revisão integrativa } \\
\text { da literatura }\end{array}$ \\
\hline $\mathrm{A} 3^{7}$ & $\begin{array}{l}\text { Angra G, Medeiros } \\
\text { MVS, Brito DTF, } \\
\text { Pimentel ERS, } \\
\text { Formiga NS, Costa } \\
\text { MML, } 2019 .\end{array}$ & $\begin{array}{l}\text { Revista Brasileira } \\
\text { de Enfermagem }\end{array}$ & $\begin{array}{l}\text { Verificar o conhecimento e prática } \\
\text { de enfermeiros no controle da dor de } \\
\text { pacientes com feridas neoplásicas. }\end{array}$ & Descritivo \\
\hline $\mathrm{A} 4^{11}$ & $\begin{array}{l}\text { Souza MAO, Souza } \\
\text { NRS, Melo JTS, } \\
\text { Xavier MACA, } \\
\text { Almeida GL, } \\
\text { Santos ICRV, } 2018 .\end{array}$ & $\begin{array}{l}\text { Revista Brasileira } \\
\text { de Enfermagem }\end{array}$ & $\begin{array}{l}\text { Verificar a existência de instrumentos } \\
\text { de avaliação do odor em feridas } \\
\text { neoplásicas. }\end{array}$ & $\begin{array}{c}\text { Revisão integrativa } \\
\text { da literatura }\end{array}$ \\
\hline $\mathrm{A} 5^{12}$ & $\begin{array}{l}\text { Castro MCF, } \\
\text { Santos WA, Fuly } \\
\text { OS, Santos MLSC, } \\
\text { Garcia TR, } 2017 . \\
\end{array}$ & Aquichan & $\begin{array}{l}\text { Identificar intervenções de enfermagem } \\
\text { para o diagnóstico de odor fétido em } \\
\text { ferida tumoral. }\end{array}$ & $\begin{array}{c}\text { Revisão integrativa } \\
\text { da literatura }\end{array}$ \\
\hline $\mathrm{A} 6^{13}$ & $\begin{array}{l}\text { Junior JF, Fuly } \\
\text { PSC, } 2019 .\end{array}$ & $\begin{array}{l}\text { Revista de } \\
\text { Enfermagem } \\
\text { UFPE on-line }\end{array}$ & $\begin{array}{l}\text { Analisar associações entre o tamanho } \\
\text { das feridas neoplásicas, odor e } \\
\text { tratamento utilizado para construção } \\
\text { de um protocolo de intervenções de } \\
\text { enfermagem. }\end{array}$ & Transversal \\
\hline $\mathrm{A} 7^{14}$ & $\begin{array}{l}\text { Fontes FLL, } \\
\text { Oliveira AC, } 2019 .\end{array}$ & $\begin{array}{l}\text { Revista } \\
\text { UNINGÁ }\end{array}$ & $\begin{array}{l}\text { Descrever as intervenções } \\
\text { do enfermeiro frente ao tratamento } \\
\text { e à avaliação de feridas oncológicas, } \\
\text { identificando também as principais } \\
\text { coberturas empregadas. }\end{array}$ & $\begin{array}{c}\text { Revisão integrativa } \\
\text { da literatura }\end{array}$ \\
\hline $\mathrm{A} 8^{15}$ & $\begin{array}{l}\text { Souza NR, Lima } \\
\text { MTC, Batista } \\
\text { RPS, Santos MAS, } \\
\text { Bushatsky M, } \\
\text { Santos ICRV } 2019 .\end{array}$ & $\begin{array}{l}\text { Cogitare } \\
\text { Enfermagem }\end{array}$ & $\begin{array}{l}\text { Verificar os aspectos relacionados à } \\
\text { prescrição, preparo e administração do } \\
\text { metronidazol para controle do odor em } \\
\text { feridas neoplásicas. }\end{array}$ & Transversal \\
\hline
\end{tabular}


Seguem, no quadro 2, os demais dados extraídos dos artigos do estudo relacionados aos principais sintomas abordados e cuidados de enfermagem. Percebe-se uma prevalência de sintomas relacionados aos cuidados de enfermagem à ferida oncológica, evidenciando-se a presença de odor (100\%); exsudato (62,5\%); relato de dor (50\%) e presença de sangramento (37,5\%). Observou-se ainda, em menor prevalência, questões referentes aos impactos psicossocial e espiritual, risco de infecção e/ou sinais de infecção local, necrose tecidual, prurido, educação permanente e preparo e administração do metronidazol, sendo cerca de $37,5 \%$.

Quadro 2 - Síntese dos estudos sobre feridas neoplásicas de acordo com os sintomas abordados e os cuidados de Enfermagem descritos.

\begin{tabular}{|c|c|c|}
\hline ARTIGOS & $\begin{array}{l}\text { SINTOMAS } \\
\text { ABORDADOS }\end{array}$ & PRINCIPAIS CUIDADOS DE ENFERMAGEM \\
\hline $\mathrm{A} 1^{10}$ & $\begin{array}{l}\text { - Odor } \\
\text { - Dor } \\
\text { - Exsudato } \\
\text { - Impacto } \\
\text { - psicológico } \\
\text { - Impacto } \\
\text { - espiritual }\end{array}$ & $\begin{array}{l}\text { - Controle ou minimização dos sintomas; } \\
\text { - A aplicação de outras escalas/ferramentas de avaliação de feridas também são } \\
\text { úteis e promovem um impacto positivo na qualidade de vida; } \\
\text { - A ferramenta TELER foca na avaliação do curativo; a Ferramenta de avaliação } \\
\text { de úlceras malignas (The Malignant Wound Assessment Tool) aborda aspectos } \\
\text { clínicos da ferida, psicológicos e sociais do paciente; } \\
\text { - Controle dos sintomas físicos. O sentimento de vergonha intensa prejudica } \\
\text { a procura por auxílio médico. O paciente esconde a lesão até se tornar } \\
\text { incontrolável e só depois procura ajuda. Causa isolamento familiar e da } \\
\text { sociedade; } \\
\text { - Fornecimento de informações completas ao paciente, tanto sobre a etiologia da } \\
\text { ferida, autocuidado, suporte emocional e como e onde encontrar esse suporte } \\
\text { - tanto para os cuidados físicos quanto emocionais. Essas informações podem } \\
\text { ser dadas através de folhetos e em linguagem acessível ao paciente; } \\
\text { - Aplicação do instrumento de autoavaliação da ferida e sintomas } \\
\text { (WoundandSymptoms Self-Assessment Chart) pode ser um caminho para a } \\
\text { abordagem de aspectos psicológicos em pacientes com maior dificuldade de } \\
\text { se abrir; } \\
\text { - Fornecimento de suporte espiritual quando necessário e se bem aceito } \\
\text { pelo paciente. O uso do instrumento Functional Assessment of ChronicIl } \\
\text { lnessTherapy (FACIT) pode contribuir para avaliar a necessidade de oferecer } \\
\text { suporte espiritual. }\end{array}$ \\
\hline $\mathrm{A} 2^{3}$ & - Odor & $\begin{array}{l}\text { - Remoção de tecido necrótico, uso de bactericida (metronidazol gel, sulfadiazina } \\
\text { de prata, neomicina, mel, iogurte), controle do exsudato com uso de coberturas } \\
\text { não aderentes e absorventes; } \\
\text { - Uso de aromatizadores; } \\
\text { - Educação e suporte à família. }\end{array}$ \\
\hline
\end{tabular}




\begin{tabular}{|c|c|c|}
\hline $\mathrm{A} 3^{7}$ & $\begin{array}{l}\text { - Odor } \\
\text { - Exsudato } \\
\text { - Sangramento } \\
\text { - Dor } \\
\text { - Necrose } \\
\text { - Infecção } \\
\text { - Impacto } \\
\text { - Psicossocial } \\
\text { - Educação } \\
\text { - Permanente }\end{array}$ & $\begin{array}{l}\text { - Odor: realizar desbridamento e limpeza da ferida; (solução limpa ou salina), } \\
\text { orientar a troca de curativo, dar orientações à família e ao paciente, avaliar/ } \\
\text { aplicar antibiótico local, orientar o uso de aromatizadores e a refrigeração do } \\
\text { ambiente; } \\
\text { - Exsudato: uso de curativo, limpeza da ferida, uso de bolsa local, proteger a } \\
\text { borda da ferida e avaliar/aplicar antibiótico local; } \\
\text { - Sangramento: uso de curativo não aderente, uso de compressa/soluções } \\
\text { frias, compressão local, uso de hemostático, orientar o paciente e a família e } \\
\text { encaminhar } \\
\text { - a cuidados médicos e serviço de emergência; } \\
\text { - Dor: manter a ferida úmida, uso de solução salina para a limpeza, proteger as } \\
\text { margens, cuidado na troca de curativos. } \\
\text { - Necrose: prover desbridamento, realizar curativo e controle } \\
\text { - de infecção; } \\
\text { - Infecção: desbridamento, curativo por técnica asséptica, avaliar/ aplicar } \\
\text { - Psicossocialerapia; oferecer apoio psicossocial, acionar equipe multidisciplinar, } \\
\text { atividades lúdicas, apoio ao paciente e à família; } \\
\text { - Educação Permanente: no que concerne à seção do conhecimento dos } \\
\text { enfermeiros, é possível observar uma prática assistencial de enfermagem frágil, } \\
\text { lacunar e incipiente, o que remete à necessidade de criação e implementação } \\
\text { de educação permanente no serviço. }\end{array}$ \\
\hline $\mathrm{A} 4^{11}$ & $\begin{array}{l}\text { - Exsudato } \\
\text { - Odor }\end{array}$ & $\begin{array}{l}\text { - Como as feridas oncológicas raramente cicatrizam, o controle dos sintomas } \\
\text { deve ser o foco principal para a manutenção da qualidade de vida; } \\
\text { - Controle do exsudato e odor: curativos absorventes e que } \\
\text { - se adequem aos contornos do corpo à base de carvão (ineficientes quando } \\
\text { saturado); uso de metronidazol tópico (ação reduzida em grandes quantidades } \\
\text { de exsudato e grande quantidade de tecido necrótico), o debridamento mecânico } \\
\text { com auxílio de bisturi não é recomendado pelo alto risco de sangramento, } \\
\text { debridamento autolítico aumenta a quantidade de exsudato; } \\
\text { - Utilização da escala TELER para mensuração do odor e escolha do curativo } \\
\text { ideal; }\end{array}$ \\
\hline $\mathrm{A} 5^{12}$ & - Odor & $\begin{array}{l}\text { - Uso de desodorizantes de ambientes; } \\
\text { - Uso de bandeja com areia para gatos no ambiente; } \\
\text { - Almofadas de ervas; } \\
\text { - Óleo essencial; } \\
\text { - Neutralizadores ambientais de odor; } \\
\text { - Colocação de tigela com pó de café no quarto; } \\
\text { - Aromaterapia (hortelã pimenta); } \\
\text { - Bicarbonato de sódio embaixo da cama; } \\
\text { - Uso de difusores aromáticos; } \\
\text { - Carvão estrategicamente espalhado pelo quarto; } \\
\text { - Uso de perfumes ou fragrâncias para mascarar o odor; } \\
\text { - Ventilação do ambiente na troca dos curativos/ abrir janelas; } \\
\text { - Uso de odores fortes: vinagre, baunilha; } \\
\text { - Disposição apropriada dos curativos sujos. }\end{array}$ \\
\hline
\end{tabular}




\begin{tabular}{|c|c|c|}
\hline $\mathrm{A} 6^{13}$ & $\begin{array}{l}\text { - Odor } \\
\text { - Exsudato } \\
\text { - Dor } \\
\text { - Sangramento }\end{array}$ & $\begin{array}{l}\text { - Abordar o paciente de maneira mais ampla, holística e empática; } \\
\text { - Oferecer apoio psicossocial; } \\
\text { - Oferecer terapias alternativas podem ser úteis para ajudar } \\
\text { - os pacientes a encontrar um equilíbrio entre o corpo, mente } \\
\text { - e espírito; } \\
\text { - Oferecer produtos adequados e modernos que sejam } \\
\text { - capazes de controlar grandes quantidades de exsudato e } \\
\text { - odor. }\end{array}$ \\
\hline $\mathrm{A} 7^{14}$ & $\begin{array}{l}\text { - Odor } \\
\text { - Exsudato } \\
\text { - Sangramento } \\
\text { - Dor } \\
\text { - Prurido } \\
\text { - Impacto } \\
\text { psicológico }\end{array}$ & $\begin{array}{l}\text { - O planejamento do cuidado deve basear-se em um roteiro } \\
\text { - de avaliação sistemática; } \\
\text { - } \text { enfermente deve ser avaliado por um especialista, como um } \\
\text { - Oferecer o cuidado adequado para o controle dos sintomas clínicos da ferida } \\
\text { (curativo adequado, uso de protetores da pele adjacente à ferida, etc); } \\
\text { - Educar o paciente, familiares e cuidadores; } \\
\text { - Oferecer terapias alternativas (massagens e terapia de } \\
\text { - toque, musicoterapia, aromaterapia); } \\
\text { - Aplicar questionário de qualidade de vida e de ansiedade } \\
\text { - para avaliar risco de depressão; } \\
\text { - Encaminhar para serviço social quando aplicável; } \\
\text { - Aplicar instrumento FICA para avaliar questões } \\
\text { - espirituais. }\end{array}$ \\
\hline $\mathrm{A} 8^{15}$ & $\begin{array}{l}\text { - Prescrição, } \\
\text { preparo e } \\
\text { administração } \\
\text { do } \\
\text { metronidazol } \\
\text { - Odor }\end{array}$ & $\begin{array}{l}\text { - Realiza limpeza da ferida com SF morno antes da aplicação } \\
\text { - do Metronidazol; } \\
\text { - Após a aplicação do metronidazol, ocluir com gaze seca; } \\
\text { - Utiliza o metronidazol juntamente com outros produtos/coberturas; } \\
\text { - Na presença de tecido necrótico endurecido, } \\
\text { - realizar escarotomia antes da aplicação. }\end{array}$ \\
\hline
\end{tabular}

De acordo com a sintomatologia abordada da ferida neoplásica, estabeleceram-se as seguintes categorias distintas: 1) Assistência de enfermagem no controle do odor e exsudato em feridas neoplásicas; 2) Cuidados paliativos de enfermagem no controle da dor e hemorragias em pacientes com feridas neoplásicas; 3) Atuação assistencial de enfermagem nos impactos psicossociais em pacientes com feridas neoplásicas em tratamento paliativo; 4) A importância da educação permanente dos profissionais de enfermagem que atuam no cuidado paliativo de pacientes com feridas neoplásicas, a ser discutida na sequência.

\section{DISCUSSÃo}

\section{Assistência de enfermagem no controle do odor e exsudato em feridas neoplásicas}

Entre os cuidados de enfermagem imprescindíveis, apontados pelos estudos, dois pontos são frequentemente abordados na prática de enfermagem relacionados às feridas neoplásicas. Em primeiro lugar, a realização adequada da avaliação da lesão e da saúde integral do paciente é apontada como fundamental para subsidiar a elaboração dos Diagnósticos de Enfermagem e a implementação de medidas de controle de sinais e sintomas, a redução 
de riscos para a saúde e a melhora da qualidade de vida do paciente. Em segundo lugar, a realização da limpeza apropriada da lesão e a escolha da cobertura a ser aplicada nas feridas neoplásicas são citadas como cuidados de enfermagem que interferem diretamente no prognóstico dos pacientes ${ }^{11}$.

No que tange à limpeza das feridas, estudos demonstram a existência de uma diversidade de soluções que podem ser aplicadas nesta etapa, dentre as quais a mais comumente utilizada na prática assistencial são as soluções antissépticas, como o soro fisiológico, água destilada, peróxido de oxigênio $(1,5-3 \%)$ e povidona iodada $10 \%^{17,19}$. Observou-se que as coberturas ajudam no tratamento por possuírem uma ação bactericida e, na prática clínica, é habitual a utilização de coberturas com ações bactericidas para a redução do odor ${ }^{18,20}$.

Desse modo, as principais coberturas descritas na literatura para as feridas neoplásicas são: o metronidazol, na apresentação como gel, creme ou comprimido (diluído em solução); coberturas com a presença de prata adicionada à fórmula, como a sulfadiazina de prata e, ainda, citam-se a neomicina e o carvão ativado como opções de cobertura. Outra opção é o desbridamento da ferida, ou seja, a remoção de tecido necrótico. Porém, este deve ser avaliado criteriosamente pelo enfermeiro pelo alto risco de sangramento, uma vez que as feridas neoplásicas são amplamente vascularizadas e apresentam um alto risco de sangramento local ${ }^{15}$.

Além disso, encontra-se significativa atenção às grandes deformidades que as feridas neoplásicas causam somadas ao odor exalado, são indicadas regularmente como "intoleráveis". Os estudos evidenciam que uma das formas mais utilizadas de se controlar o odor é com a utilização do metronidazol, que consiste em um antibiótico ativo contra bactérias anaeróbicas e protozoários, que exerce atividades antibacteriana, antiparasitária e anti-helmíntica ${ }^{15}$. Este medicamento atua pela captação e ativação intracelular e isto se explica pelo fato de que os elétrons, que transportam proteínas necessárias para a reação intracelular, só são encontrados na bactéria anaeróbica. Dentro da célula, exercerá suas propriedades citotóxicas interagindo com o DNA, produzindo perda da estrutura helicoidal, ruptura da cadeia e consequente inibição da síntese de ácidos nucleicos e morte celular ${ }^{15,21}$.

O controle de exsudato das lesões neoplásicas constitui um dos cuidados importantes na assistência de enfermagem. A presença de exsudato está associada à presença de infecção que surge em decorrência da própria estrutura tumoral, produção celular e à criação de novos vasos pelo processo de angiogênese, sendo fatores que favorecem o aparecimento e a proliferação de bactérias ${ }^{21}$. Para o controle de exsudato, os estudos evidenciam que a utilização de coberturas absortivas como o alginato, a espuma de poliuretano e o curativo constituído por hidrofibra são coberturas indicadas para o leito das lesões por apresentarem ação bactericida em decorrência da composição de prata. Além disso, outro aspecto importante que deve ser considerado pelos profissionais da enfermagem é o cuidado com a borda da ferida neoplásica com exsudato. A presença abundante de exsudato pode ocasionar maceração e dificuldade de cicatrização, portanto, deve-se proteger ao redor. Assim, para proteger a borda da ferida o enfermeiro não deve utilizar uma cobertura com dimensão superior ao da borda da ferida, uma vez que esse tipo de cobertura sobre a pele estimula a produção de calor e a transpiração e, consequentemente, aumenta as chances de maceração. Além disso, os cuidados com os pacientes com feridas neoplásicas incluem a atenção da equipe de enfermagem nas trocas da cobertura, que deve ser realizada periodicamente ${ }^{7,21}$.

\section{Cuidados paliativos de enfermagem no controle da dor e hemorragias em pacientes com feridas neoplásicas}

Os estudos apresentam uma preocupação na 
avaliação e no controle da dor através de analgésicos e anestésicos locais ${ }^{7}$, no que diz respeito aos momentos de troca de curativo da ferida neoplásica. Nesse sentido, os estudos apontam que o uso de soluções/cremes tópicos ou a administração via oral de medicações analgésicas e anti-inflamatórios, por exemplo, podem agir de modo efetivo. Além do mais, a utilização de medidas simples possibilita o controle da dor, tais como: o uso de coberturas antiaderentes; o cuidado ao remover o curativo; o uso de irrigação de solução abundante para prevenir lesão secundária, como de terminações nervosas; proteger as margens e a aplicação de crioterapia local ${ }^{7,20,21}$.

O cuidado com a hemorragia proveniente da ferida neoplásica é outra assistência que deve ser realizada pelos profissionais de enfermagem aos pacientes. Os estudos indicam que tais cuidados incluem condutas medicamentosas e não medicamentosas. Entre as condutas não medicamentosas na assistência de enfermagem, incluem-se o cuidado na remoção dos curativos; a irrigação abundante; o uso de coberturas não aderentes; o uso de compressão local e o uso de crioterapia ${ }^{10}$. Nas condutas medicamentosas, utilizase o nitrato de prata, a adrenalina (epinefrina) e o ácido aminocaproico aplicados no leito da ferida. Além disso, como cobertura a ser utilizada pelo enfermeiro, no controle do sangramento, o uso de alginato de cálcio e hemostáticos como, por exemplo, o Surgicel ${ }^{\circledR 14}$.

\section{Atuação assistencial de enfermagem nos impactos psicossociais em pacientes com feridas neoplásicas em tratamento paliativo}

Nesta categoria, podem ser citados os aspectos relacionados ao paciente e à família. Assim, os estudos mostram que é necessário que o enfermeiro elabore um plano de cuidados que atenda às necessidades relatadas pelo paciente e familiares ${ }^{21,14}$. Os estudos evidenciam que a presença de lesões neoplásicas interfere diretamente na autoestima do paciente, o que o leva ao isolamento social. Nesse sentido, torna-se importante oferecer apoio psicológico e emocional e atividades que auxiliem a autoestima. Por isso, estudos sugerem, por exemplo, a aromaterapia, a musicoterapia, os grupos de apoio, a terapia ocupacional ${ }^{6,8,21}$. Salienta-se, quanto aos cuidados à família, que é fundamental o enfermeiro ensinar como auxiliar na realização dos curativos do paciente e inserir como ícone no plano de cuidados ${ }^{22 .}$ Além disso, o comportamento do paciente é afetado na presença de lesões neoplásicas, emergindo sentimento de raiva, estigma, solidão, desânimo e, consequentemente, influência negativa no bem-estar mental. Desse modo, o apoio familiar é essencial e o enfermeiro pode atuar sendo um elo importante de ligação entre o paciente e a família, ajudando a superar as dificuldades de lidar com a presença do tumor ${ }^{22,16}$.

A importância da educação permanente dos profissionais de enfermagem que atuam no cuidado paliativo de pacientes com feridas neoplásicas

A análise dos estudos demonstrou que a maior parte dos enfermeiros apresentam limitações no conhecimento para avaliar as especificidades da lesão, indicar a cobertura adequada, o tipo de curativo a ser utilizado no controle dessas lesões, bem como diagnosticar adequadamente todas as necessidades dos pacientes.

Outro aspecto preocupante é a omissão da assistência de enfermagem direcionada a estes pacientes. Provavelmente, essas limitações estão relacionadas à ausência de educação permanente no serviço de saúde e àeducação continuada em áreas afins, tais como: dermatologia, estomaterapia, cuidados paliativos, dentre outras ${ }^{23}$. Acredita-se que as falhas na realização da avaliação e tratamento de pacientes com feridas neoplásicas estejam relacionadas a fatores como o déficit do conhecimento relacionado aos conteúdos e técnicas no cuidado às feridas neoplásicas; aumento da carga de trabalho devido às atividades gerenciais; mal planejamento do 
dimensionamento de pessoal, de insumos e de materiais para a avaliação de feridas, assim como produtos, substâncias e coberturas escassos no serviço de saúde ${ }^{24}$.

A literatura evidencia que a educação permanente dos profissionais de enfermagem que atuam na assistência de pacientes com lesões neoplásicas constitui-se a base para a assistência de qualidade. Nesse sentido, os estudos assinalam a necessidade da educação permanente no serviço de saúde, a fim de treinar a equipe de enfermagem para o acompanhamento de pacientes com lesões neoplásicas, instituição de protocolos de assistência para o cuidado de cada tipo de lesão e atendimento holístico ao paciente e aos familiares ${ }^{20,23,13}$.

\section{CONCLUSÕES}

Os cuidados paliativos de enfermagem em pacientes com feridas neoplásicas objetiva a redução de sinais e sintomas físicos como o controle de odores, exsudatos, hemorragias, dores e minimização de sofrimento psicossocial em pacientes com neoplasias sem possibilidade de cura.

Os estudos evidenciam que a avaliação apropriada da lesão, a instituição de coberturas ideais de acordo com a especificidade de cada paciente e a redução do sofrimento biopsicossocial são fundamentais para garantir a qualidade de vida. Entretanto, tais fatores têm sido apontados como desafios para a assistência dos profissionais de enfermagem, devido à existência de lacunas de conhecimento em grande parte dos profissionais da área, o que interfere diretamente no alcance de uma assistência qualificada. Desta forma, a educação permanente tem sido apontada como o melhor meio para a busca na melhoria da assistência de enfermagem a pacientes com feridas neoplásicas.

Espera-se que este estudo traga contribuições relevantes que demonstrem a importância do profissional de enfermagem na assistência ao paciente oncológico, principalmente no que concerne ao cuidado da ferida neoplásica e, mais além, que possa despertar o interesse das equipes especializadas para a continuidade desta pesquisa e aprofundamento de tema tão valioso no campo do atendimento humanizado em Cuidados Paliativos.

\section{REFERÊNCIAS}

1. Vicente C, Amante LN, Santos MJ, Alvarez AG, Salum NC. Cuidado à pessoa com ferida oncológica: educação permanente em enfermagem mediada por tecnologias educacionais. Rev Gaúcha Enferm. 2019 [ acesso em 2020 abr 26]; 40:e20180483. Disponível em: http://www.scielo. br/scielo.php?pid=S1983-14472019000100429\&script=sci_ arttext.

2. Brasil. Instituto Nacional de Câncer José Alencar Gomes da Silva. Estimativa 2016: incidência de câncer no Brasil [Internet]. Rio de Janeiro: Author; 2015 [acesso 2020 abr 26]. Disponível em: http://www.inca.gov.br/bvscontrolecancer/ publicacoes/edicao/Estimativa_2016.pdf.

3. Santos WA, Fuly PSC, Santos MLSC, Souto MD, Reis CM, Castro MCF. Avaliação do isolamento social em pacientes com odor em feridas neoplásicas: revisão integrativa. Rev de Enferm UFPE. 2017 [acesso em 2020 abr 24]; 11(Supl. 3):1495-1503. Disponível em: < https://periodicos.ufpe.br/ revistas/revistaenfermagem/article/download/13995/1 6861 $>$.

4. Soares RS, Cunha DAO, Fuly PSC. Cuidados de enfermagem com feridas neoplásicas. Rev Enferm UFPE on-line. 2019 jan [acesso em 2020 abr 17]; 13(1):3456-63. Disponível em: file://D:/Backup\%20Autom\%C3\%A1tico/ Downloads/236438-129228-1-PB\%20(2).pdf.

5. Nogueira WP, Agra G, Formiga NS, Costa MML. Perfil sociodemográfico, clínico e terapêutico de pacientes com feridas neoplásicas. Rev Enferm UFPE on-line. 2017 ago [acesso em 2020 abr 17]; 11(8):3039-49. Disponível em: https://pesquisa.bvsalud.org/portal/resource/pt/bde-32526.

6. Fontes FLL, Oliveira AC. Competências do enfermeiro frente à avaliação e ao tratamento de feridas oncológicas. Rev UNINGÁ. 2019 jan./mar [acesso em 2020 abr 19]; 56(Supl.2):71-79. Disponível em: http://revista.uninga.br/ 
index.php/uninga/article/view/2158.

7. Agra, G, Medeiros MVS, Brito DTF, Pimentel ERS, Formiga NS, Costa MML. Conhecimento e prática de enfermeiros no controle da dor de pacientes com feridas neoplásicas. Rev Enferm Bras 2019 [acesso em 2020 abr 23]; 18(1):3-11. Disponível em: http://dx.doi.org/10.33233/ eb.v18i1.1039.

8. Instituto Nacional do Câncer. Brasil. Tratamento e controle de feridas tumorais e úlceras por pressão no câncer avançado. Série Cuidados Paliativos. Rio de Janeiro: INCA; 2011 [acesso em 2020 mai 05]. Disponível em: https:// www.inca.gov.br/.

9. Souza MT, Silva MD, Carvalho R. Revisão integrativa: o que é e como fazer. Einstein. 2010 [ acesso em 2020 mai 05]; 8(1Pt1): 102-6. Disponível em: file://D:/ Backup\%20Autom\%C3\%A1tico/Downloads/pt_1679-4508eins-8-1-0102.pdf..

10. Freitas MSHS, Pacheco PQC, Souza SR. A qualidade de vida do paciente portador de feridas neoplásicas: uma revisão integrativa. Rev Enf Atual In Derme. 2016 [acesso em 2020 abr 23]; 88(26). Disponível em: https:// revistaenfermagematual.com.br/index.php/revista/article/ view/438.

11. Souza MAO, Souza NRS, Melo JTS, Xavier MACA, Almeida GL, Santos ICRV. Escalas de avaliação de odor em feridas neoplásicas: uma revisão integrativa. Rev Bras Enferm [Internet]. 2018 [acesso em 2020 abr 24];71(5):255260. Disponível em: http://dx.doi.org/10.1590/0034-71672017-0428.

12. Castro MCF, Santos WA, Fuly OS, Santos MLSC, Garcia TR. Intervenções de enfermagem para pacientes oncológicos com odor fétido em ferida tumoral. Aquichan. 2017 [acesso em 2020 abr 18].17(3). Disponível em: https:// www.redalyc.org/jatsRepo/741/74155184002/html/index. html.

13. Ferreira JJ, Fuly PSC. Análise de associação entre feridas neoplásicas, odor e tratamento: estudo transversal. Rev Enferm UFPE on-line. 2019 ago [acesso em 2020 abr 20]; 8(8):2938-40. Disponível em: 10.5205/reuol.6081-523281-SM.0808201449.

6. Fontes FLL, Oliveira AC. Competências do enfermeiro frente à avaliação e ao tratamento de feridas oncológicas. Rev UNINGÁ. 2019 jan./mar [acesso em 2020 abr 19]; 56(Supl.2):71-79. Disponível em: http://revista.uninga.br/ index.php/uninga/article/view/2158.

15. Souza NR, Lima MTC, Batista RPS, Santos MAS, Bushatsky M, Santos ICRV. Prescrição e uso de metronidazol para controle do odor em feridas neoplásicas. Cogitare Enferm. [Internet]. 2019 [acesso em 2020 abr 26]; 24. Disponível em: http://dx.doi.org/10.5380/ce.v24i0.57906.

16. Santos WA, Fuly OS, Santos MLSC, Souto MD, Reis CM, Beretta LL. Evidências sobre o isolamento social em pacientes com exsudato em feridas neoplásicas: revisão integrativa. Rev Enferm Atual. 2017 [acesso em 2020 abr 19]; 81(19). Disponível em: https://pesquisa.bvsalud.org/ portal/resource/pt/biblio-1023923.

17. Barreto AM, Marques ADB, Cestari VRF, Cavalcante RC, Moreira TMM. Efetividade do metronidazol no tratamento de odores em feridas tumorais. Rev Rene. 2018 [acesso em 2020 mai 01];19:e3245. Disponível em: https://pdfs.semanticscholar.org/aa64/ fcd749bb9519a996510c2881b452145f4fdc.pdf.

18. Prado ARA, Barreto VPM, Tonini T, Silva AS, Machado WCA. O saber do enfermeiro na indicação de coberturas no cuidado ao cliente com feridas. Rev Estima. 2016 [acesso em 2020 abr 24]; 14(4): 175-18. Disponível em: < https://www.revistaestima.com.br/index.php/estima/article/ download/430/pdf $>$.

19. Lisboa IND, Valença MP. Caracterização de Pacientes com Feridas Neoplásicas. Estima. 2016 [acesso em 2020 mai 01];14(1):21-28. Disponível em: https://pdfs.semanticscholar. org/7850/601b0916387f337b35a8705d7e92643dcfbb.pdf.

20. Narciso AC, Souza NR, Souza MAO, Abrão FMS, Luz GOA, Santos ICRV. Variáveis associadas ao controle do odor em feridas neoplásicas: conhecimento para o cuidado de enfermagem. Rev Enferm UERJ. Rio de Janeiro. 2017 [acesso em 2020 abr 26]; 25:e26036. Disponível em: http:// dx.doi.org/10.12957/reuerj.2017.26036.

21. Brito DTF, Pereira IKC, Agra G, Macêdo EL, Dantas JS, Almeida TLC. Feridas neoplásicas em pacientes com câncer de mama. Ver Enferm Atual. Brasil. 2018 [acesso em 2020 mai 01];17(6):606-618. Disponível em: https://doi. org/10.33233/eb.v17i6.2063.

22. Andrade FLM, Agra G, Sousa ATO, Brito DTF, Gomes RF, Pimentel RRS. Conhecimento de enfermeiras sobre avaliação e manejo clínico de pacientes com ferida neoplásica. Rev Enferm Atual. 2018 [acesso em 2020 mai 01]; 85. Disponível em: http://dx.doi.org/10.31011/1519- 
Silva EVS, Conceição HN

339X.2018a18n85.05.

23. Agra G, Medeiros MVS, Brito DTF, Andrade FLM, Pimentel ERS, Costa MML. Conhecimento e prática de enfermeiros no controle de feridas neoplásicas. Rev Enferm Atual. 2017 [acesso em 2020 mai 05]; 81. Disponível em: file://D:/Backup\%20Autom\%C3\%A1tico/Downloads/549Texto\%20do\%20artigo-1731-1-10-20191012\%20(1).pdf.

24. Vicente C, Amante LN, Santos MJ, Alvarez AG, Salum NC. Cuidado à pessoa com ferida oncológica: educação permanente em enfermagem mediada por tecnologias educacionais. Rev Gaúcha Enferm. 2019 [acesso em 2020 mai 05];40:e20180483. Disponível em: http://dx.doi. org/10.1590/1983-1447.2019.20180483 